Dear Author,

Please, note that changes made to the HTML content will be added to the article before publication, but are not reflected in this PDF.

Note also that this file should not be used for submitting corrections. 


\title{
Q2 Stakeholder perceptions of Environmental Management Plans as an environmental protection tool for major developments in the UK
}

\author{
Q3 Sophie Bennett ${ }^{\mathrm{a}}$, Simon Kemp ${ }^{\mathrm{a}}$, Malcolm D. Hudson ${ }^{\mathrm{a}, \mathrm{b}, *}$ \\ Q4 a Faculty of Engineering and the Environment, University of Southampton, SO17 1BJ, United Kingdom \\ 5 b Institute for Life Sciences, University of Southampton, S017 1BJ, United Kingdom
}

\section{A R T I C L E I N F O}

Article history:

Received 1 July 2015

Received in revised form 18 September 2015

Accepted 18 September 2015

Available online $\mathrm{xxxx}$

\begin{abstract}
A B S T R A C T
Insufficient implementation and the lack of legislative requirements for follow-up measures following the 14 approval of projects are consistently highlighted as major shortcomings of Environmental Impact Assessment 15 (EIA). Although adopted over 15 years ago by the World Bank, Environmental Management Plans (EMPs) 16 were only semi-formalised in the UK in 2008 and arguably provide a continuous link or 'bridge' between the 17 EIA process pre-consent and an Environmental Management System (EMS) post-consent. Drawing on twenty- 18 one semi-structured interviews with stakeholders and thematic analysis of their responses, and a broad-scale 19 practitioner survey, this study aimed to assess the effectiveness of EMPs as an environmental protection tool 20 across the project lifecycle for major developments. The findings revealed a mixed picture of EMP effectiveness 21 in practice, with EMPs only partially fulfilling a bridging role between EIA and EMS. There is no 'gold standard' 22 terminology for EMPs, all having slightly different uses, thus presenting different focuses to different stakeholders 23 and further enhancing variation in practice. For many stakeholders, the effectiveness was simply not known, due 24 to the lack of communication and follow-up that still exists. EMP-EMS linkages were shown to be effective from 25 the developer's perspective when a single organisation has involvement across all project phases, though weak- 26 nesses occur when multiple parties are involved. Among other stakeholders, knowledge varied significantly; 27 whilst some were in agreement that the linkages worked, many were unaware of the connections and thought 28 of them as two quite separate tools. Stakeholders advocated for the need to make EMPs a legal requirement; 29 for improved communication between stakeholders during EMP implementation and increased documentation 30 of project outcomes; and for EMPs to be consistently written by environmental professionals. Furthermore, weak 31 links in the current process may be improved by providing detailed guidance for organisations on the potential 32 for EMP-EMS linkages, with the additional aim of encouraging stakeholders to broaden their current specialist 33 knowledge on environmental protection tools.

(C) 2015 Published by Elsevier Inc. 35

\section{Introduction}

Insufficient implementation of follow-up measures, and the distinct lack of legislative requirements following the approval of projects, have consistently been highlighted as major shortcomings of Environmental Impact Assessment (EIA), with literature subsequently questioning the overall effectiveness of EIA as an environmental protection tool (Wood, 1999; Nitz \& Holland, 2000; Gallardo \& Sanchez, 2004; Gallardo \& Sanchez, 2004; Jay et al., 2007; Morrison-Saunders et al., 2007). EIA follow-up can be defined as the monitoring and evaluation of the impacts of a project or plan (that has been subject to EIA) for management of, and communication about, the environmental performance of that project or plan (Arts et al., 2001). Such shortcomings exist despite the World Bank establishing guidance in 1999 on Environmental

* Corresponding author at: Faculty of Engineering and the Environment, University of Southampton, SO17 1BJ, United Kingdom.

E-mail address: mdh@soton.ac.uk (M.D. Hudson).
Management Plans, documents established in order to provide a 53 continuous link between predicted impacts and the measures specified 54 to mitigate them (Durning, 2012).

However, a new EU Directive on EIA (2014/52/EU) includes the 56 introduction of mandatory monitoring for significant adverse effects 57 (Article 8) with the aim to correct what is arguably the biggest flaw in 58 the existing regime. More so than ever, applying follow-up within EIA 59 is no longer an option by a sound precaution and proactive measure 60 to ensure a sustainable future (Marshall, 2004).

\subsection{Integration of EIA and EMS}

62

An EIA is carried out prior to a development taking place with the 63 aim of minimising significant environmental effects (Glasson et al., 64 2013). Environmental impacts created during and post-development 65 are controlled through environmental management practices based 66 upon legislative requirements or internal policies. An Environmental 67 Management System (EMS) is one means of managing ongoing impacts 68 
during, and post completion of the development. Although an EMP might not stipulate a certificated EMS, organisations may choose to demonstrate externally verified credibility to their environmental practices through a formal EMS such as one certified to the International Organisation of Standardisation (ISO) ISO14001 (ISO, 2015). A certified EMS will involve the review, assessment and continual improvement of an existing organisation's environmental effects (Glasson et al., 2013). An EMS is said to have both tangible benefits in aspects such as reducing waste (e.g. Briggs, 2006), and intangible environmental performance improvements; for instance improved environmental awareness among employees (e.g. Rondinelli \& Vastag, 2000) and has been adopted as global tool for environmental improvement with over 300,000 organisations certified in 171 countries (ISO, 2013). It should be noted that application of both a certified EMS such as ISO14001 and a non-certified EMS is voluntary, unless it is stipulated by a regulator as a legal condition of a permit to operate.

Both EIA and EMS can be seen as environmental protection tools that have complementary purposes, with EIA seeking to anticipate and mitigate/enhance impacts of proposed new projects at the planning and design stage, and EMS helping organisations to effectively manage the subsequent day-to-day impacts (Obradovic, 2011). Thus, within the 'environmental management toolbox' (Finkbeiner et al., 1998), they can be linked to manage environmental impacts across the development project lifecycle (Slinn et al., 2007; Hollands \& Palframan, 2014).

Various theoretical approaches to linking EIA and EMS have been proposed (e.g. Ecclestone \& Smythe, 2002; Sanchez \& Hacking, 2002; Ridgway, 2005; Perdicoulis \& Durning, 2007; Slinn et al., 2007; Perdicoulis et al., 2012). Such studies highlight a range of barriers that can hinder integration (Palframan, 2010), including challenges around the legal and policy framework (e.g. Ecclestone \& Smythe, 2002); technical issues (e.g. Slinn et al., 2007); practitioner issues (e.g. Sanchez \& Hacking, 2002); and proponent and stakeholder attitudes (e.g. Marshall 2004). It is widely acknowledged that there is most potential for linking EIA with EMS where organisations plan their own development for which they also oversee construction and/or occupy in the long term (Marshall, 2004; Slinn et al., 2007; Palframan, 2010).

\subsection{Environmental Management Plans}

Environmental Management Plans (EMPs) are one way of mitigating and managing the environmental effects of development projects (IEMA, 2008), defined as documents that 'outline the mitigation, monitoring and institutional measures to be taken during project implementation and operation to avoid or control adverse environmental impacts, and the actions needed to implement these measures' 111 (Tinker et al., 2005).

The overall objective of an EMP is to provide a continuous link or 113 'bridge' between the EIA process pre-consent and the EMS operated 114 by various stakeholders (e.g. project construction contractors, project 115 operation managers) post-consent (IEMA, 2008; Glasson et al., 2013) 116 (Fig. 1). Furthermore, where an organisation has an EMS, the EMP 117 may refer to relevant policies and procedures within it, and a propo- 118 nent's EMS may include processes for the preparation of EMPs. As 119 such, recent experiences have described EMPs as a less formal, less 120 bureaucratic, 'EMS-lite' approach (Marshall, 2002, 2004, 2005). 121

Around the world there has been some take-up of EMPs as part of 122 the EIA process by, for example, the World Bank (see above) and in spe- 123 cific locations such as Western Australia (Dik and Morrison-Saunders, 124 2002) and Hong Kong (Durning 2012) or in specific sectors such as 125 Environmental Action Plans in flood risk management works overseen 126 by the UK Environment Agency (Fuller et al. 2012). There is no general 127 statutory requirement for project proponents to deliver all mitigation 128 proposed pre-consent or to prepare EMPs in the UK, and as such, their 129 use varies significantly within sector, organisation and scheme (IEMA, 130 2008). The UK Institute of Environmental Management and Assessment 131 (IEMA) has been a strong advocate of the EMP approach, and set out its 132 position in its Practitioner Guide (IEMA, 2008). Prior to this, there has 133 been little existing guidance available in relation to the production 134 and implementation of EMPs.

135

The focus on EMPs within the academic literature is limited in scope. 136 Early studies have identified issues associated with the use of EMPs in 137 practice as a result of the need for voluntary uptake (Boyden, 2002; Q9 Mohamad-Said, 2002). The origins and the links EMPs can make between 139 EIA and EMS have recently been explored by Durning (2012) through the 140 review of current literature, noting their variation in practice, and their 141 focus on construction rather than operational impacts (e.g. Broderick \& 142 Durning, 2006; Broderick et al., 2010). Most notable is perhaps a string Q10 of studies by Marshall $(2002,2004,2005)$ documenting a single case 144 study and advocating that, in the absence of statutory requirements, the 145 development of an EMP will be motivated by a proponent/developer's 146 individualistic desire to satisfy specific project requirements or for them 147 to fit within existing management frameworks such as their EMS. 148

It is worth clarifying that the integration of EIA and EMS has received 149 little attention in the literature; and it is complicated by a range of 150 terminology and differing approaches to the level of independence of 151 those involved in oversight of any monitoring. The World Bank and 152 the International Finance Corporation set overarching performance 153 standards related to sustainability, and typically have a requirement 154 for environmental supervisors to oversee construction activities. The 155

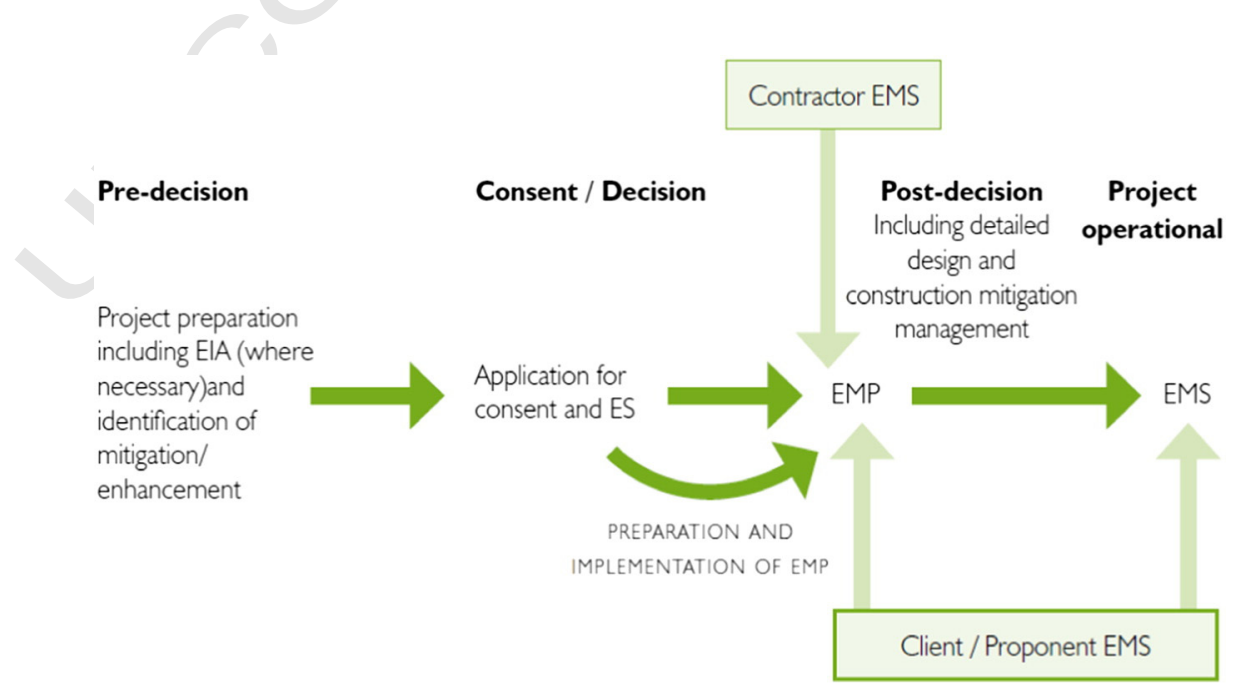

Fig. 1. Linkages between EIA, EMPs and EMS (IEMA, 2008). 
terminology for such supervision varies, with 'environmental control officer' in use in South Africa and 'independent environmental checker' in Japan, both of which are usually independent of the developer (Wessels, 2013).

\subsection{The study aims}

In light of such limited literature on EMPs, the overwhelming desire for adequate EIA follow-up, and the more stringent requirements for monitoring in the 2014 EIA Directive (2014/52/EU), this study aims to assess the effectiveness of EMPs - as perceived by stakeholders - as an environmental protection tool across the project lifecycle for major development projects in the UK. We have defined 'effectiveness' as being whether impacts considered significant in the EIA process have been averted and/or mitigated effectively, based on the overall aim of the EMP being to 'ensure that the effort put into the EIA process preapplication and consent is effectively delivered post-consent' (Glasson et al., 2013).

This research represents the first broad-scale focus on EMPs by taking a sector-wide approach and involving a range of stakeholders who were given the opportunity to reflect on their experiences and express their views in in-depth interviews and via a wider questionnaire survey of the EIA professional community. The focus of the research was on the effectiveness of EMPs as environmental protection tools across the construction and operational phases, on the value of linkages with institutional EMSs, and to update and advance the effectiveness of EMPs where relevant for future practice.

\section{Methodology}

\subsection{Semi-structured interviews with stakeholders}

Twenty one semi-structured face-to-face interviews with stakeholders were undertaken from June to July 2014. The interviewees were from ten consultancies and five developers, four local planning authorities and two UK statutory consultees (i.e. government agencies with a formal role in EIA), chosen to reflect the different stakeholders involved.

The range of interviewees were chosen by making initial telephone enquiries to organisations. Potential candidates were selected by providing an overview of the intended scope of the research; those that confirmed having experience writing, using, and/or reviewing EMPs (involvement dependent on stakeholder) were deemed suitable candidates. An email was sent with a more detailed description of the research, allowing candidates to confirm that they had suitable experience with EMPs, or providing them with an opportunity to pass on to a more suitable candidate, and thus ensuring that the most suitable interviewees made themselves available.

An in-depth, semi-quantitative review of academic literature available on EMPs revealed four key subject areas for exploration, providing the framework for the interviews (Holbrook et al., 2003) and a starting point to stimulate further discussion (e.g. Hammond \& Hudson, 2007; Hollands \& Palframan, 2014). The interviewees were asked for their views and experiences with reference to the following subject areas:

\section{The effectiveness of EMPs in providing environmental protection for} the construction and operational phases;

2. The monitoring and follow-up requirements in EMPs;

3. The EMP-EMS linkages:

(a) Does your company have an EMS and does this affect how you carry out your activities?

(b) From past experiences, do you feel that the presence of an EMS enhances the practice of organisations you are working with?

(c) From past experiences, does an EMS document processes for preparing and monitoring/auditing the EMP?

216

(d) From past experiences, does the EMP provide a mechanism for 217 the EMS to takeover in the operational phase?

4. Suggestions for improving the effectiveness of EMPs.

It should be noted that the third subject area was subsequently split 222 into further related subject areas in order to explore the different 223 aspects of EMP-EMS linkages. These subjects varied depending on the 224 type of stakeholder, however, and were more relevant to developer in- 225 terviewees; this was made clear to participants in such cases. 226

All interviews lasted between 15 and $60 \mathrm{~min}$, with the majority last- 227 ing for approximately $30 \mathrm{~min}$. Interview-related error was reduced by 228 following guidelines outlined in Oppenheim (1992); for example, the 229 interviewee was initially asked to briefly describe both the organisa- 230 tion's and their own involvement with major development projects, 231 and then EMPs, ensuring the respondent's co-operation was readily 232 forthcoming and that terminology was understood. The use of non- 233 directive probes, as recommended by Foody (1993) allowed inter- 234 viewees the opportunity to expand on their comments without being 235 led. Confidentiality has been provided for each of the interviewees; 236 identities and affiliations are not revealed, so interviewees are referred 237 to anonymously as Consultant 1 (C1, C2 etc.), Local Authority 1 (LA1, 238 LA2 etc.) and so on.

Following completion, interviews were fully transcribed from the 240 recordings as an edited verbatim transcript, removing unnecessary 241 stop words whilst retaining accuracy (e.g. Hollands \& Palframan, 242 2014). Examination of interview content under the four key subject 243 areas was based on the 'thematic analysis' methodology as outlined by 244 Braun and Clarke (2006). Thematic analysis is a method for identifying, 245 analysing and reporting patterns (themes) within data (Braun and 246 Clarke, 2006). A theme captures something important about the data 247 in relation to the research question, and represents some level of pat- 248 terned response or meaning within the data set. Through its theoretical 249 freedom, thematic analysis provides a flexible and useful research tool, 250 and is thus widely used by qualitative researchers (Ritchie and Spencer, 251 1994; Fink, 2003; Braun and Clarke, 2006).

For each of the four exploratory subject areas, transcripts were 253 coded and recurring themes and sub-themes were identified, allowing 254 comparisons to be made within and between stakeholders (Braun and 255 Clarke, 2006). Such analysis is beneficial, enabling the movement back 256 and forth between different levels of abstraction without losing sight 257 of the raw data (Siedman, 2006). The process of transcription is seen 258 as a 'key phase of data analysis within the interpretative qualitative 259 methodology' (Bird, 2005), allowing the researcher to become familiar 260 with the data. For each of the exploratory subject areas, transcripts 261 were manually coded, and codes were then sorted and allocated into 262 overarching 'themes'; thematic maps were used to assist this process, 263 enabling the relationships between codes, between themes, and be- 264 tween different levels of themes to be thoroughly considered (Braun 265 and Clarke, 2006).

Themes were then identified in an inductive or 'bottom up' way, 267 which describes a process of coding the data without trying to fit it 268 into a pre-existing coding frame (Braun and Clarke, 2006). It should 269 also be noted that themes were identified at a 'semantic' level 270 (Boyatzis, 1998); with a semantic approach, the themes were identified 271 within the explicit or surface meanings of the data and we did not look 272 for anything beyond what an interviewee said. For the reader's informa- 273 tion, recurrences of themes have been quantified. However, it should be 274 noted that, in the case of thematic analysis, more instances do not nec- 275 essarily mean the theme itself is more crucial. As such, researcher judge- 276 ment has been used to determine what a theme is, and themes have 277 been allocated to standalone comments if they are deemed as 'capturing 278 something important in relation to the overall research question' 279 (Braun and Clarke, 2006). 


\section{Results}

Table 1
An online survey was produced and sent to the Chartered Institute of Ecology and Environmental Management (CIEEM) and the Association of Local Government Ecologists (ALGE) for inclusion in their e-newsletter to members, and the survey featured on an online discussion page for members of the Institute of Environmental Management and Assessment (IEMA). These professional membership bodies are UK-wide, allowing an extensively dispersed sample to be contacted. The survey was also sent to professionals whom interviewees had advocated as additional contacts suitable for interviews, but for which time was limited.

A set of questions were developed comprising nine closed and three open questions, designed to reflect the four main subject areas covered in the stakeholder interviews (Fink \& Kosekoff, 1998) (see Supplementary Information A). A pilot study involving a variety of stakeholders working in the industry was performed to ensure that the study was clearly explained and the questions easily understood (Fink, 2003). A brief explanation providing the background to the research was provided and confidentiality was ensured, to allow for maximum response rate. Results are presented as percentages without further quantitative analysis due to low response rates.

\subsection{Semi-structured interviews with expert stakeholders}

The views of the interviewees regarding the four main subject areas are drawn together below. Key details including a quantitative summary of the responses are highlighted in Tables 1-4.

For Subject Area 1, it became apparent that for all local authority and statutory consultee interviewees, the effectiveness of EMPs as an environmental protection tool was simply not known (Table 1). Commonly recurring sub-themes were that stakeholders were of the opinion that the effectiveness is dependent on the implementation of the EMPs; the construction phase is the primary focus; and that EMPs are only effective when project-specific. In addition, a statutory consultee noted the effectiveness of an EMP varied depending on the type, commenting "I find Construction Environmental Management Plans (CEMPs) quite rigid, identifying the risks and this is how you manage that risk, whereas
Ecological Management Plans go beyond that, and goes to great lengths 316 to try to start exploring the possibilities of Ecosystem Services. 317

Similarly for Subject Area 2 exploring monitoring and follow-up re- 318 quirements, the fact that stakeholders didn't get updated following EMP 319 implementation was a common theme for all local authority partici- 320 pants, statutory consultees and the majority of consultants (Table 2). 321 The desire from statutory consultees and consultants to be updated in 322 order to learn for future practice, and to voluntarily follow-up on 323 novel mitigation strategies, were recurring themes. Developer inter- 324 viewees noted the importance of an Ecological Clerk of Works (ECW), 325 although their use was disputed by consultants. A standalone response 326 from a developer interviewee highlighted; "We undertake monitoring 327 that makes up part of the planning conditions, but I am never pushed for 328 the survey results. Interestingly I have just got the final monitoring report 329 for a new scheme - I will be amazed if anybody actually chased me for it. 330 I know that's not right but in practice I think that is the reality" (D1). 331

Subject Area 3 posed the links between EMPs and EMS (Tables 3.1 \& 332 3.2). It became apparent that statutory consultee and local authority 333 interviewees were unfamiliar with both these links and EMS as an 334 environmental management tool. Opinions on whether the presence 335 of an organisation's EMS makes for better practice varied between and 336 within stakeholder groups (Subject Area 3a \& b). All developer inter- 337 viewees were in agreement that their EMS provides a framework for 338 producing and monitoring an EMP, but consultants were of varied 339 opinions (Subject Area 3c), whilst Subject Area 3d, presented to just de- 340 veloper interviewees, produced a mixed response, with two inter- 341 viewees advocating an apparent gap existing between the EMP and 342 the ongoing EMS.

Subject Area 4 drew on the opinions for improving the effectiveness 344 of EMPs in practice (Table 4). The most common recommendation was 345 the apparent desire for EMPs to become a legal requirement. The impor- 346 tance of increased professional involvement was felt strongly by local 347 authority interviewees, whilst consultants and developers advocated 348 for improvements to the way the EMP is communicated on site and 349 between stakeholders.

\subsection{Online practitioner survey}

In total, there were 41 responses to the survey. General information 352 was collected to put the findings into context, including which 353

Subject Area 1 - The effectiveness of EMPs providing environmental protection for the construction and operational phases.

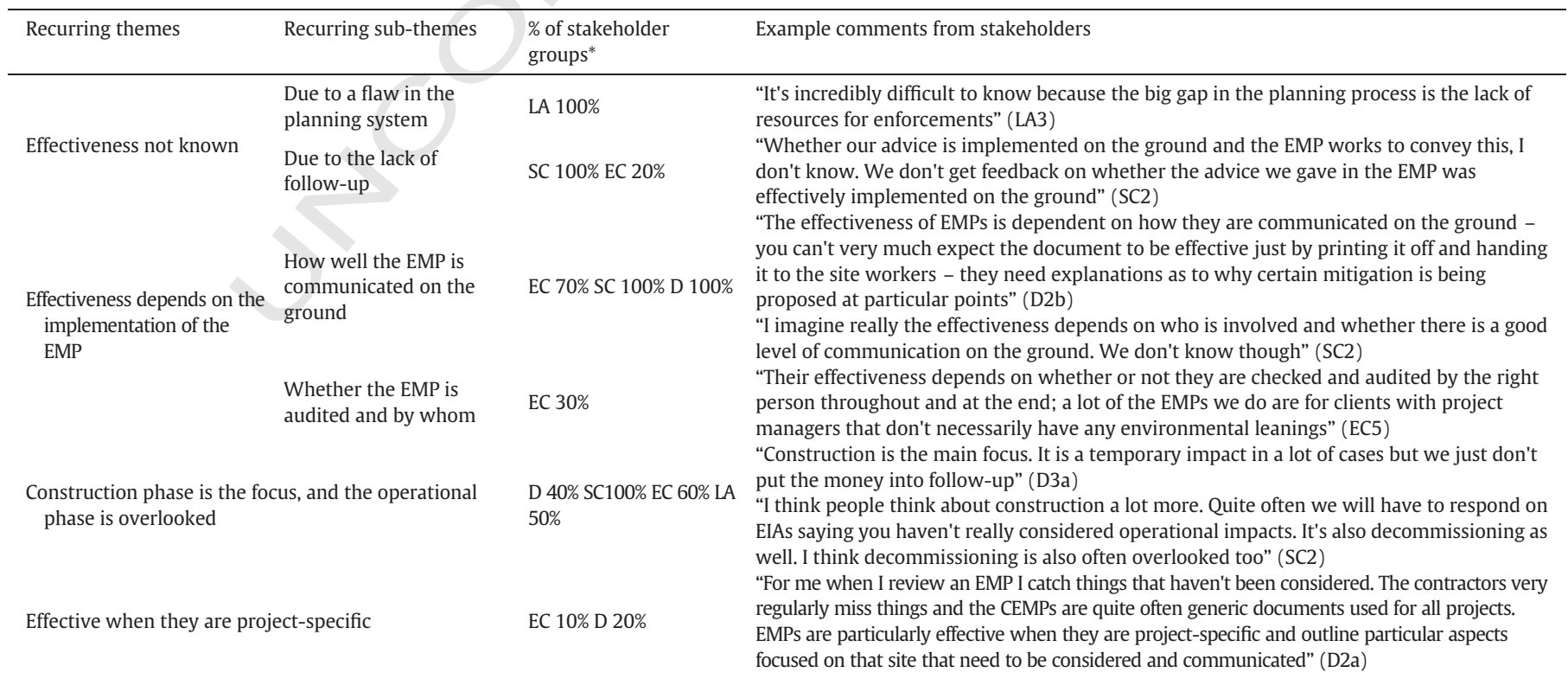

t1.13 * ${ }^{*} \mathrm{~L}=$ Local Authority $(\mathrm{N}=4), \mathrm{SC}=$ Statutory Consultee $(\mathrm{N}=2), \mathrm{EC}=$ Environmental Consultant $(\mathrm{N}=10), \mathrm{D}=$ Developer $(\mathrm{N}=5)$. 
Table 2

Subject Area 2 - the monitoring and follow-up requirements in EMPs.

\begin{tabular}{|c|c|c|c|}
\hline Recurring themes & Recurring sub-themes & $\begin{array}{l}\text { \% of stakeholder } \\
\text { groups* }\end{array}$ & Example comments from stakeholders \\
\hline \multirow{3}{*}{$\begin{array}{l}\text { Stakeholders don't get } \\
\text { updated }\end{array}$} & $\begin{array}{l}\text { Rarely informed of monitoring } \\
\text { surveys }\end{array}$ & LA $100 \%$ & $\begin{array}{l}\text { "We set the conditions, but we are not informed of the monitoring results or how anything is } \\
\text { going. I hope they submit them but I don't get informed" (LA1) }\end{array}$ \\
\hline & $\begin{array}{l}\text { A lack of resources to } \\
\text { follow-up }\end{array}$ & LA $50 \%$ EC $30 \%$ & $\begin{array}{l}\text { "We don't have the time to follow up on our conditions or monitor ourselves - we move on to } \\
\text { the next project - the work load that is there means that there isn't the capacity. And the cuts } \\
\text { have made it particularly bad" (LA3) }\end{array}$ \\
\hline & $\begin{array}{l}\text { Not updated on the outcomes of } \\
\text { the development project but } \\
\text { would like to know for future } \\
\text { practice }\end{array}$ & SC $100 \%$ EC $80 \%$ & $\begin{array}{l}\text { "If it is not conditioned, there is no legal mechanism for us to be consulted. Which is where the } \\
\text { weakness is, that feedback loop isn't working, and sometimes we will provide advice and we } \\
\text { won't hear about the decision. So we would have to go onto the Planning Portal website to see } \\
\text { if it has been approved or not. We quite often won't get feedback but we'd like to know for } \\
\text { future projects" (SC2) }\end{array}$ \\
\hline \multirow[t]{2}{*}{$\begin{array}{l}\text { Site managers provide } \\
\text { effective monitoring }\end{array}$} & $\begin{array}{l}\text { An ECW is effective when } \\
\text { familiar with the scheme }\end{array}$ & EC $20 \%$ & $\begin{array}{l}\text { "When we are able to see the project from beginning to end then our ECW role is extremely } \\
\text { valuable, but very often we are only contracted to produce an EIA, we don't get contracted to } \\
\text { do anything further once construction starts, so we hand over that documentation and } \\
\text { whoever is contracted to do the next phase will have to pick that up and run with it, and will } \\
\text { cause problems" (EC2) }\end{array}$ \\
\hline & $\begin{array}{l}\text { ECWs are important for } \\
\text { developers }\end{array}$ & D $80 \%$ & $\begin{array}{l}\text { "It is vital that we make sure that site inspections are undertaken to ensure the environment is } \\
\text { protected and any follow-up monitoring can be delivered" (D2a) }\end{array}$ \\
\hline \multicolumn{2}{|c|}{$\begin{array}{l}\text { Depends on the developer/who is managing the land } \\
\text { afterwards }\end{array}$} & LA 75\% D 20\% & $\begin{array}{l}\text { "My own personal view is that it depends on the company's approach to it, and I say that } \\
\text { because I don't think there is any regulator engagement or involvement" (D1) }\end{array}$ \\
\hline \multicolumn{2}{|c|}{$\begin{array}{l}\text { Innovative mitigation strategies can result in follow-up } \\
\text { exceptions }\end{array}$} & SC $50 \%$ EC $10 \%$ & $\begin{array}{l}\text { "Quite often where the mitigation is quite novel, for example habitat creation at a managed } \\
\text { realignment site, and we will quite often be involved in this; people are interested to know } \\
\text { because it's quite a new thing and no one is quite sure how these sites will develop" (SC2) }\end{array}$ \\
\hline
\end{tabular}

${ }^{*} \mathrm{LA}=$ Local Authority $(\mathrm{N}=4), \mathrm{SC}=$ Statutory Consultee $(\mathrm{N}=2), \mathrm{EC}=$ Environmental Consultant $(\mathrm{N}=10), \mathrm{D}=$ Developer $(\mathrm{N}=5)$.

stakeholder group participants belonged to, what terms for EMPs they were most familiar with (in total fourteen different terms were mentioned), how often they dealt with EMPs, and in what context they were mainly used. Although not evenly distributed, respondents represented all stakeholders: fourteen local authorities, sixteen consultants, four developers, three contractors, two statutory consultees and two non-governmental organisations (NGOs). The majority of practitioners (95\%) dealt with EMPs either 'all the time' or 'fairly regularly', thus indicative of a high level of knowledge.

There was an apparent general consensus among stakeholders that EMPs are effective environmental protection tools during the construction phase (Fig. 2); however, their effectiveness during the operational phase was less highly regarded (Fig. 3). Respondents were asked 366 whether the presence of a contractor and/or proponent's EMS led to 367 improved practice; $51 \%$ of respondents answered 'yes sometimes', and 368 $37 \%$ of respondents were unsure as to whether it did lead to improved 369 practice or not.See Fig. 4

Following this, respondents were asked if any alterations could be 371 made to improve the effectiveness of EMPs. Among stakeholders, 88\% 372 were in agreement that improvements were needed; the most recur- 373 ring suggestions for improvements can be seen in Fig. 3. Standalone 374 comments included the desire for better communication on site, 375 advocated by a consultant, and the need for an on-site ecologist, 376 suggested by an NGO worker.

Table 3.1

Subject Area 3 - The EMP-EMS Linkages.

\begin{tabular}{|c|c|c|c|}
\hline Recurring themes & Recurring sub-themes & $\begin{array}{l}\% \text { of stakeholder } \\
\text { groups* }\end{array}$ & Example comments from stakeholders \\
\hline \multicolumn{4}{|c|}{ 3A. Does your company have an EMS and does this affect how you carry out your activities? } \\
\hline \multirow[t]{3}{*}{$\begin{array}{l}\text { Yes the organisation has } \\
\text { an EMS (or similar) }\end{array}$} & $\begin{array}{l}\text { Yes it does contribute to } \\
\text { better practice }\end{array}$ & $\begin{array}{l}\text { EC } 50 \% \\
\text { D100\% }\end{array}$ & $\begin{array}{l}\text { "Yes we have an EMS and it documents a lot of valuable information that improves and encourages } \\
\text { best practice at the company level and the individual level" (EC1) }\end{array}$ \\
\hline & & & $\begin{array}{l}\text { "We have got two EMSs - that's the ISO14001 and the EMAS - and how it has worked is that that process } \\
\text { has been developed by our technical EMS team, and so the core principals are embedded within everything } \\
\text { that we do, and therefore affects good practise" (D3a) }\end{array}$ \\
\hline & $\begin{array}{l}\text { Yes but not aware of the } \\
\text { contents of the EMS }\end{array}$ & EC $50 \%$ & $\begin{array}{l}\text { "We have an EMS. This is maintained and kept up to date. Although funnily enough the } \\
\text { environmental team don't have that much involvement with it" (EC3) }\end{array}$ \\
\hline \multirow{2}{*}{\multicolumn{2}{|c|}{$\begin{array}{l}\text { A lack of involvement and interest, and so do not } \\
\text { know }\end{array}$}} & SC $100 \%$ & "We have an EMS definitely, but if I'm honest, I really don't know much about the contents of it and so \\
\hline & & LA $100 \%$ & I'm not sure if it affects good practice" (SC2) \\
\hline
\end{tabular}

3B. From past experiences, do you feel that the presence of an EMS enhances the practice of organisations you are working with?

Yes it does $\quad$ Yes it does contribute to EC 70\% "I think most of the time the presence of an EMS certainly does improve good practice for organisations we

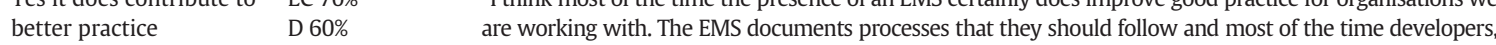
contractors etc. follow all the necessary steps and seem environmentally aware, in my opinion" (EC6) "I think it does help, but I think often it will come down to the attitude to the specific people involved, so perhaps there is a behavioural element to it, it very much depends on the individuals involved, their experience, where they are coming from" (EC2)

Yes, but perhaps only at a D $40 \%$ very basic level $\quad$ EC $30 \%$ a basic thing. If you have a massive organisation, they are never going to get down to the project level that you are working on" (D2b)

A lack of involvement and interest, and so do not know SC 100\% "We are not really involved in this. It's not really something that we as a consultee think about, and I'm LA $100 \%$ afraid I don't know" (SC1)

${ }^{*} \mathrm{LA}=$ Local Authority $(\mathrm{N}=4), \mathrm{SC}=$ Statutory Consultee $(\mathrm{N}=2), \mathrm{EC}=$ Environmental Consultant $(\mathrm{N}=10), \mathrm{D}=$ Developer $(\mathrm{N}=5)$. 
t4.2 Subject Area 3 - The EMP-EMS Linkages.

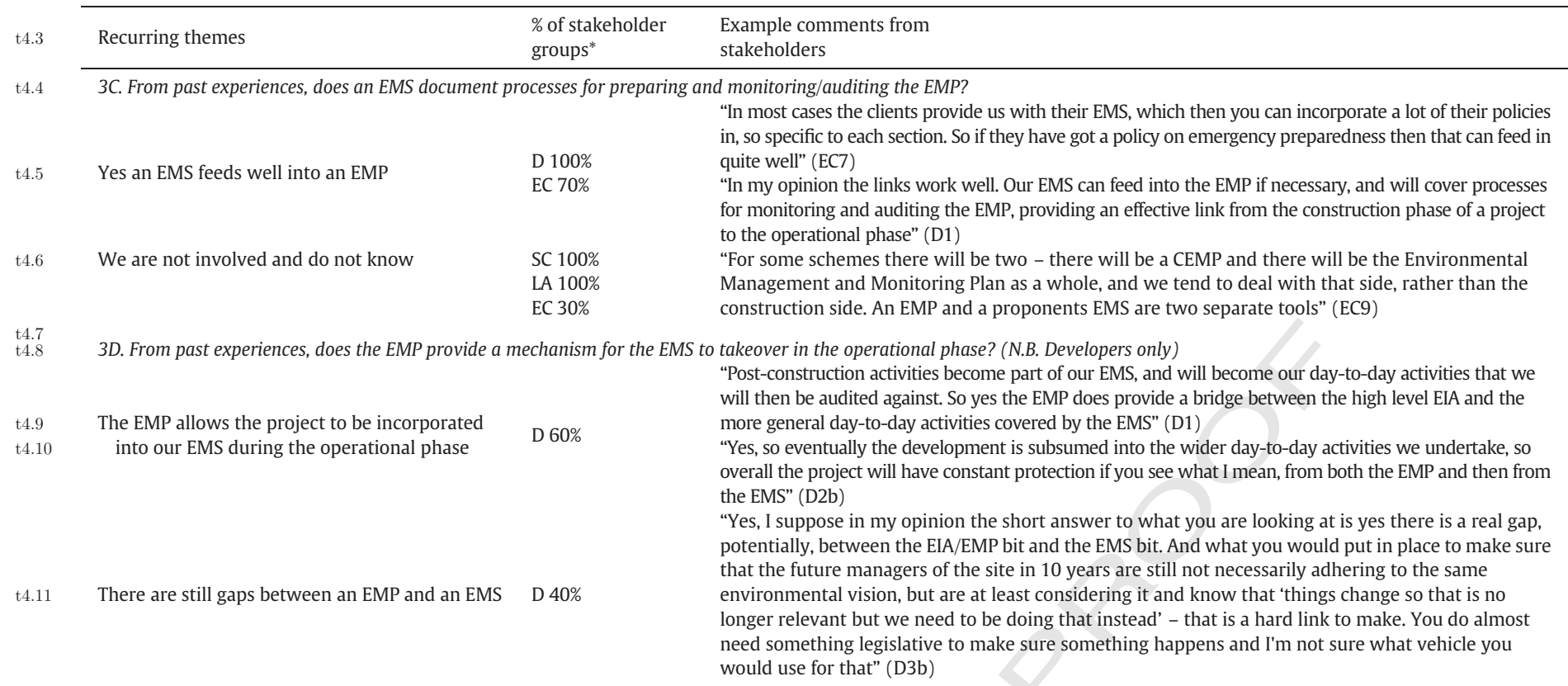

${ }^{*} \mathrm{LA}=$ Local Authority $(\mathrm{N}=4), \mathrm{SC}=$ Statutory Consultee $(\mathrm{N}=2), \mathrm{EC}=$ Environmental Consultant $(\mathrm{N}=10), \mathrm{D}=$ Developer $(\mathrm{N}=5)$.

\section{Discussion}

\section{Variation of protection across the project life-cycle}

Interviewees indicated a significant variation in the use of EMPs in practice, and thus the effectiveness of EMPs providing protection was said to differ. This variation was noted between and within stakeholders; the majority of consultants and developers, for example, highlighted that when it was possible for the EMP to be communicated to those on the ground during the construction phase, then they were very effective. However, one consultant and one developer were under the impression that the effectiveness was dependent on the way the EMP was written, with project-specific EMPs being more effective than generic EMPs.

Such variation can be further highlighted by noting that EMPs were referred to using fourteen different names, including Construction EMP (CEMP), Habitat Management Plan, and Construction Method Plan, to name a few, all having slightly different uses. It became evident that an EMP as an EIA follow-up tool presents different meanings to different people; for some, if an EMP is well written and project-specific, then protection is guaranteed, whilst others view an EMP more as a plan that requires further guidance during implementation. These variations in practice agree with the findings of a recent scoping exercise of a randomised sample of EMPs produced between 2003 and 2010, showing wide variations in the remit of the EMP, with some being standalone documents and some chapters within Environmental Statements (Durning, 2012). It is also noted in this study that some are specific in the monitoring and auditing measures to be adopted in the EMP whilst others less specific, indicating variations in the level of environmental protection (Durning, 2012).

Furthermore, both data streams indicated that the effectiveness of EMPs was known more for the construction phase, justified by the tendency for EMPs to be construction-focused whilst the operational phase is largely overlooked. Such findings align with a study by Broderick \& Durning $(2006,2010)$ that details the effectiveness of an EMP providing environmental protection during the construction of a high pressure natural gas pipeline, but providing a lack of reference to the operational phase protection measures. Durning (2012) further emphasised such findings by noting the tendency to concentrate the use of EMPs at the construction stage of the development, identifying the need for the 415 EMP to link into the long term operation and ultimate decommissioning 416 stage of a development. It seems that further emphasis on the operation 417 phase within the EMP is still very much required.

Monitoring and follow-up requirements are rarely addressed

A frequent shortcoming of the EIA process heavily documented in 420 academic literature is the insufficient implementation of follow-up 421 measures (e.g. Wood, 1999; Nitz \& Holland, 2000; Sánchez \& Hacking, 422 2002; Gallardo \& Sanchez, 2004; Jay et al., 2007; Morrison-Saunders 423 et al., 2007). Despite the increasing presence of EMPs as a follow-up 424 tool for major development projects (Tinker et al., 2005; Durning, 425 2012), a recurring theme for statutory consultee and local authority in- 426 terviewees was the fact that they were never adequately informed of 427 the monitoring and follow-up requirements, advocated by all local au- 428 thority interviewees as a major flaw in the UK planning system. One 429 local authority interviewee describes "From my experience, monitoring 430 and mitigation is always missed off. Unless we set conditions, follow-up is 431 not addressed, and even with conditions set, we are rarely informed of 432 the results" (LA3). Although an absence of EIA follow-up is common 433 knowledge within literature, the specific follow-up flaws related to 434 the use of EMPs have been considerably under-studied thus far, due to 435 the lack of research spanning the range of stakeholders involved, 436 representing a clear focus for future improvements. 437

A benefit of EIA follow-up, in addition to the environmental protec- 438 tion that can be gained across the project lifecycle, is the extension of 439 knowledge for future practice (Arts et al., 2001). Consultants and statu- 440 tory consultees highlighted an apparent desire to be informed about the 441 mitigation put in place and the monitoring results in order to build upon 442 knowledge for upcoming projects, in an ideal world creating a virtuous 443 circle of good practice, follow-up reporting and knowledge sharing. 444 Some interviewees also advocated the need for a central database 445 with access to the overall outcomes of projects, in order to develop 446 knowledge for future practice. Impracticalities were, however, associat- 447 ed with these improvements; for example, Statutory Consultee 2448 commented "The problem is there is a lot of data out there but it is not ac- 449 cessible, because it is commercially owned by people". Such disconnects 450 are evident in a report by Lewis et al. (2014) examining mitigation of 451 
t5.1 Table 4

t5.2 Subject Area 4 - suggestions for improving the effectiveness of EMPs.

\begin{tabular}{l}
\hline Recurring themes \\
\hline $\begin{array}{l}\text { Increased professional } \\
\text { involvement }\end{array}$
\end{tabular}

Recurring sub-themes

$\%$ of stakeholder Example comments from stakeholders groups*

$\begin{array}{lc}\text { t5.7 } & \text { Improved reporting } \\ \text { t5.8 } & \text { style }\end{array}$

\section{Written by an experienced} professional

More involvement from the Environmental Clerk of Works (ECW)

Improved writing style

Increased flexibility within the EMP

EMPs should be a legal requirement under the EIA

The need to make legal requirements

Improved Monitoring

Monitoring should be enforced

Improved monitoring feedback

Information needs to be shared

Increased communication on site

Better communication

Increased communication between stakeholders

LA $75 \%$

LA $100 \%$

EC 20\%

LA 75\%

EC 10\%

EC $20 \%$

SC $50 \%$

D 20\%

LA 100\%

EC 20\%

SC $100 \%$

LA 100\%

EC $30 \%$

EC 10\%

SC $50 \%$

EC $30 \%$

D $40 \%$

EC 10\%

D 20\%
"I think it is vital that CEMPs are written by an experienced professional with background knowledge of environmental issues, and includes everything" (LA2)

"For me the suitably qualified part is vital, making sure that the document is actually used, i.e. audited against, and that that is done by someone who is suitably qualified, preferably the ECW. This needs to happen for every project, not just a few" (EC2)

"I think they are effective as long as they are well structured and not too wordy, and not too much heavy detail. Getting this balance is tricky but needs to be improved" (EC6)

"I would like EMPs to be more flexible and to include Ecosystem Services, I think this would encourage people to be a bit more broader in their thinking" (SC1)

"We need clear permission from government that it is perfectly acceptable to condition an EMP" (LA3)

"Some measure/requirement that we could enforce that would require the developer to report back on the features that they have been required to install" (LA3)

"I'd like to know the outcome for a majority of schemes I have worked on, but don't hear much once I move on to the next job" (EC7)

"I would like to see EMPs and the information that has gone into them be put a central place online as a way of sharing the information" (EC5)

"A lot of it comes down to implementation; I can't emphasise enough how pointless a piece of paper is unless someone is actually responsible for delivering it" (EC1)

"I would like there to be regular Steering Committees set up. There needs to be more communication between stakeholders" (D1)

${ }^{*} \mathrm{LA}=$ Local Authority $(\mathrm{N}=4), \mathrm{SC}=$ Statutory Consultee $(\mathrm{N}=2), \mathrm{EC}=$ Environmental Consultant $(\mathrm{N}=10), \mathrm{D}=\mathrm{Developer}(\mathrm{N}=5)$.

protected great crested newt Triturus cristatus populations associated with housing developments in the UK-; the authors suggest that the creation of a centralised accessible database could improve accountability and promote good practice.

Such aspirations for continued involvement and the need to be updated are also reflected by the international community. The key findings of a workshop on EIA follow-up conducted at IAIA'000 Back to the Future (the 20th Annual Meeting of the International Association of Impact Assessment held in 2000) that identified future directions for further development of successful EIA follow-up found that "Openness, reporting and public participation in EIA follow-up is an important issue for strengthening follow-up practices. All stakeholders should be involved. Information sharing enhances local capacity building with benefits for proponents, regulators and local communities alike" (Arts et al., 2001, p. 183). Similar findings are highlighted by Morrison-Saunders \& Arts (2004), and it seems that, after over a decade of recognition, such communication and reporting is still a desired action that is yet to be executed effectively within EIA follow-up.

What certainly is encouraging is the voluntary EIA follow-up that was said to be undertaken for more innovative mitigation strategies by several consultees. Despite its South African context, a recent study by Wessels (2013) on independent verification highlighted several factors that influence EIA follow-up, categorised under five headings 474 to include financial, commercial, professional, personal, and other; 475 such research offers valuable insight into factors influencing follow-up 476 measures. Such voluntary follow-up of innovative mitigation strategies 477 can also be linked to the motivations for adopting an EMS, which is also 478 voluntary; motivations often include the desire to increase competitive 479 advantage, the preference for getting beyond regulatory compliance, 480 and the desire to extend environmental management standards to 481 suppliers (Morrow and Rondinelli, 2002).

However, for both interviewees who conveyed these opinions, 483 overriding issues of time, as a result of human and financial resources 484 not being allocated to follow-up, were limiting factors. Similarly, for 485 the majority of interviewees who explained a lack of follow-up, the 486 issue of time inhibiting the follow-up of projects was commonly 487 expressed. Such limitations have been expressed in a study by Arts 488 et al. (2001) noting that provision of adequate resource in terms of 489 both finances and capacity is essential to make EIA follow-up reality. $\quad 490$

Also notable was the discrepancy of opinions on the roles of different 491 stakeholders and their involvement with EIA follow-up, perhaps 492 reflective of the broader issue of a lack of communication between 493 stakeholders (Arts et al., 2001). For example, a local authority partici- 494 pant (LA1) was of the impression that it is the developer's role to 495

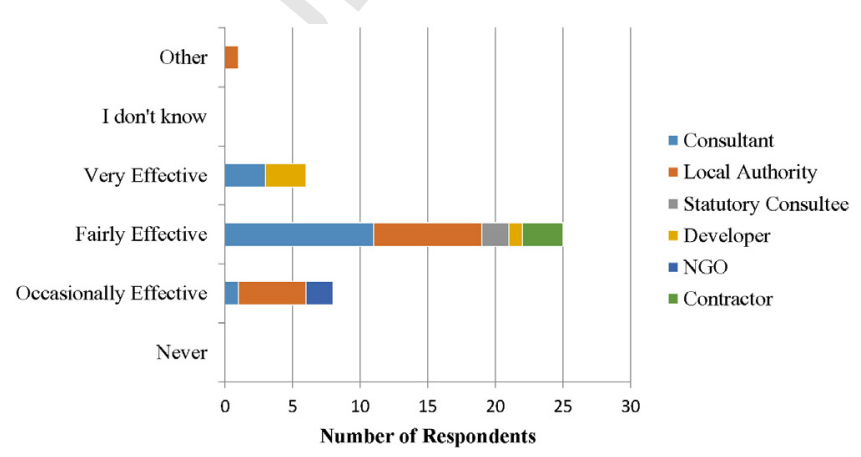

Fig. 2. Practitioner survey responses to the effectiveness of EMPs providing environmental protection during the construction phase of development projects.

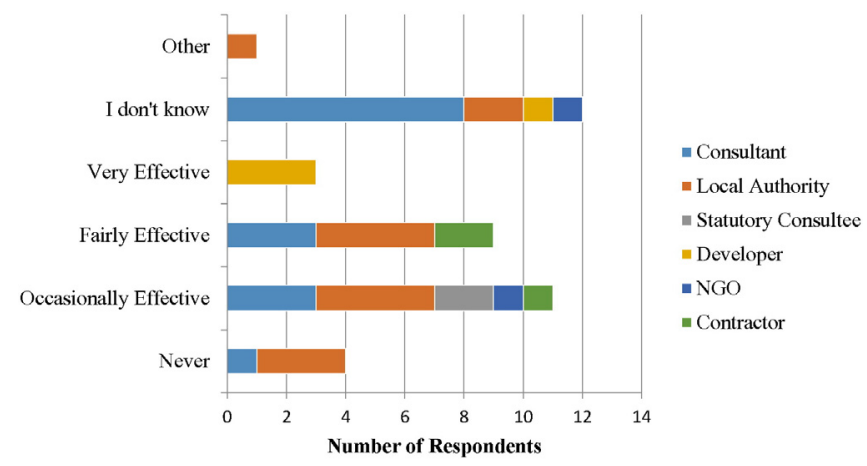

Fig. 3. Practitioner survey responses to the effectiveness of EMPs providing environmental protection during the operational phase of development projects. 


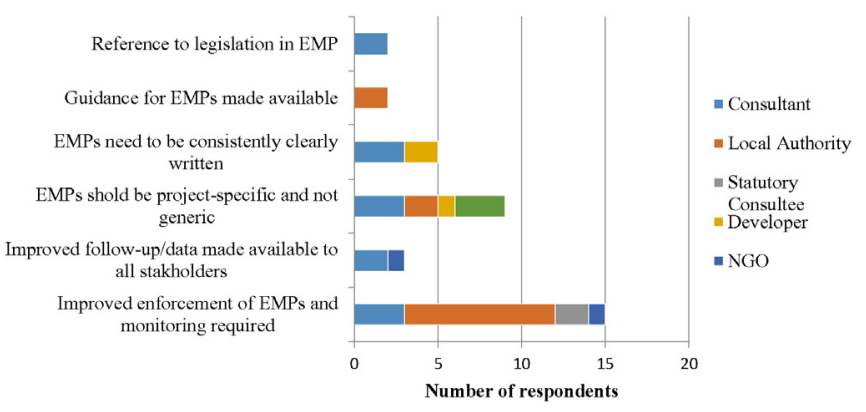

Fig. 4. Suggestions for improvements to EMPs by practitioner survey respondents. feedback EMP monitoring surveys to the regulators. Statutory Consultee 496 2, however, stated that "whoever has issued the permission should be 497 enforcing the condition and requesting monitoring results" whilst 498 Developer 1 was under the impression that monitoring is undertaken 499 but no one is "chasing them" for it. Such conflicting opinions indicate 500 a clear need for stakeholder roles to be more clearly identified to ensure 501 adequate follow-up for future practice. This aspect also surfaced as a 502 requirement to improve follow-up practice in the use of conditions 503 and contracts following EIA; the importance of clearly identified roles 504 for follow-up activities has been identified in examples from the UK 505 (Boyden, 2002; Marshall, 2002), among other studies in other countries 506 (Morrison-Saunders et al. 2003).

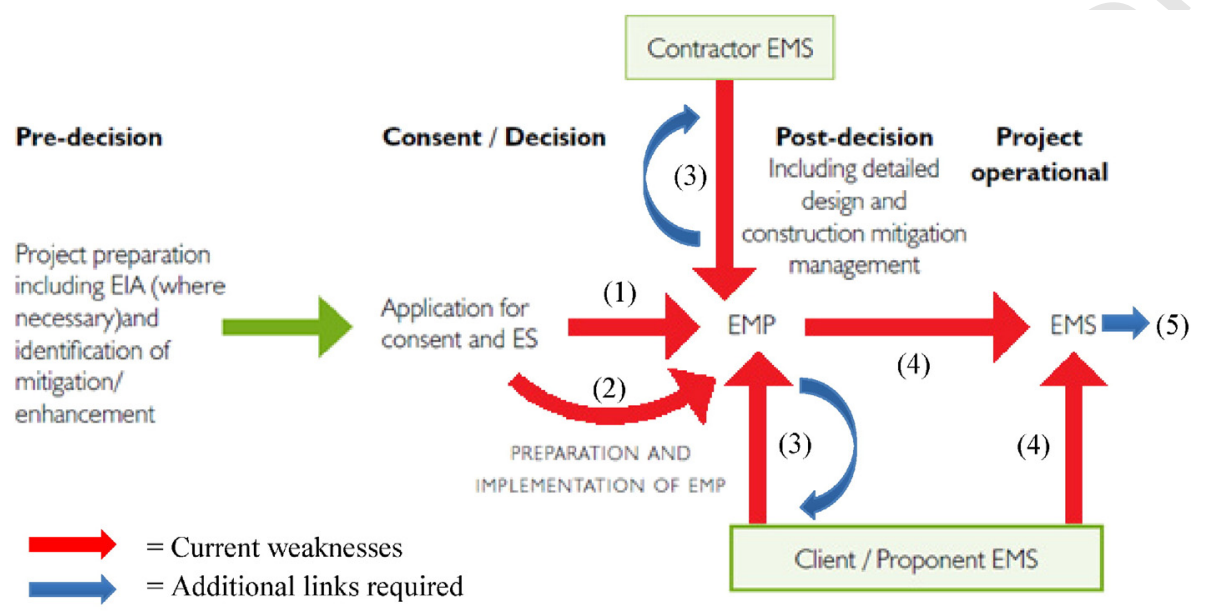

\begin{tabular}{|c|c|c|}
\hline & Current weaknesses & Suggested improvements \\
\hline (1) & $\begin{array}{l}\text { Even when conditions for } \\
\text { monitoring in the EMP are set by } \\
\text { the regulators, they are not being } \\
\text { informed of the outcomes. }\end{array}$ & $\begin{array}{l}\text { EMPs and monitoring requirements within } \\
\text { them to become a legal requirement under } \\
\text { the EIA Directive. }\end{array}$ \\
\hline (2) & $\begin{array}{l}\text { EMPs vary in how they are written, } \\
\text { who they are written by, and how } \\
\text { they are communicated on the } \\
\text { ground, thus leading to a variation } \\
\text { in the effectiveness of EMPs. The } \\
\text { structure of EMPs has also been } \\
\text { noted as too rigid. }\end{array}$ & $\begin{array}{l}\text { EMPs need to be consistently project- } \\
\text { specific, written by environmental } \\
\text { professionals, and communicated on the } \\
\text { ground to the range of stakeholders to } \\
\text { ensure the EMP is well understood. } \\
\text { Increased flexibility within the EMP is } \\
\text { needed to adapt to each project. }\end{array}$ \\
\hline (3) & $\begin{array}{l}\text { Stakeholders have noted the } \\
\text { presence of 'generic CEMPs' } \\
\text { which reiterate a contractor and/or } \\
\text { proponent's EMS within the EMP } \\
\text { rather than being project-specific. }\end{array}$ & $\begin{array}{l}\text { Guidelines explaining how an EMS can be } \\
\text { successfully implemented into an EMP } \\
\text { framework would improve practice. EMPs } \\
\text { are 'live' documents, and so links between } \\
\text { the EMP and EMS should exist so that } \\
\text { alterations can be made if needed. }\end{array}$ \\
\hline (4) & $\begin{array}{l}\text { Information from the EMP is lost } \\
\text { when different site managers are } \\
\text { involved at different phases of a } \\
\text { project. }\end{array}$ & $\begin{array}{l}\text { Project-specific information within the } \\
\text { EMP needs to be retained for different site } \\
\text { managers to refer back to. Thus, future } \\
\text { developments on that site can refer to any } \\
\text { previous mitigation put in place. Improved } \\
\text { communication between stakeholders is } \\
\text { also vital during project handovers. }\end{array}$ \\
\hline (5) & $\begin{array}{l}\text { Stakeholders are not being } \\
\text { informed of the monitoring results } \\
\text { and the overall success of the } \\
\text { project but have shown a desire to } \\
\text { learn for future practice. }\end{array}$ & $\begin{array}{l}\text { Stakeholders advocated for a central } \\
\text { database documenting the outcomes of past } \\
\text { cases and monitoring results in order to } \\
\text { learn and develop knowledge for future } \\
\text { practice. }\end{array}$ \\
\hline
\end{tabular}

Fig. 5. Apparent current weaknesses and recommendations for improving EMPs as a follow-up tool for the future, based on the semi-formalised process highlighted by IEMA (2008). 
Linkages between EMPs and EMS varies in practice and is poorly understood

The linkages between EMPs and EMS were the least understood topics of discussion, proving a challenge for many of the interviewees to build upon for several reasons. Most interviewees admitted that they had never thought about the links that EMPs can make with an EMS, with one consultant stating "Each development is seen in its own right far too much to link in with a proponent's EMS" (EC9). Such a disconnection between environmental management tools has also been found to be the case by Hollands \& Palframan (2014) in which some interviewees claimed that EIA and EMS were not linked as they were seen as "two quite separate and distinct functions". These findings align with the broader conclusions of Ridgway (2005) who highlights that EIA and EMS tend to be the responsibility of different specialists due to their different skill sets.

Further reflective of Ridgway (2005) is the lack of knowledge and disinterest shown in EMS by local authority and statutory consultee interviewees; one statutory consultee interviewee remarked "To be honest I have never even heard of EMS, and it doesn't interest me" (SC1). The focus for the local authority interviewees was their specific role within the process, in one case being the need to see the monitoring surveys stated in the EMP; "I'm not aware or interested in what is in their EMS. I'm looking at what surveys they have done, and whether or not the surveys have informed the EMP" (LA1). A related problem that has arisen in the literature is the limited number of practitioners specialising in both tools, as emphasised by Sánchez \& Hacking (2002) and Marshall (2004). There exists a strong need to improve the awareness of both EMS as an environmental protection tool and as a promoter of positive corporate behaviour, and the links that can be built with EMPs, across all stakeholders involved. Of course, encouragement for stakeholders to "branch out' certainly is an ask when challenges of time and money are so central in the equation. Growth in awareness may be driven by international drivers, but it remains to be seen how the implementation of the new EIA Directive 2014/52/EU, and any updates to guidance, promote the need for increased awareness of ongoing environmental protection tools. Furthermore EMS represents a growing opportunity for environmental improvement given its reach round the world. For example, China has recently shown the fastest growth in certifications globally (ISO, International Organization for Standardization, 2013), so a more integrated approach could have wide benefits.

The links between the two environmental tools were better understood by developers and consultant interviewees who belonged to organisations that often acted as contractors for projects too. For these consultants, "our EMS will document what should be incorporated into the CEMP if we are writing one for our own development, and alternatively when we are writing an EMP or CEMP for a client, we would ask to look at their policies (often part of their EMS) so that we can include all the relevant bits" (EC5). For those consultants working for external clients, it was also made clear that the client's EMS was taken into consideration and relevant information incorporated into the EMP when writing. Knowledge beyond the production of the EMP was, however, limited; whether the EMS effectively 'took over' the operational management of the scheme was generally not known. Such a finding relates back to the lack of follow-up, particularly for the operational phase, that is currently in existence across the process (Arts et al., 2001; MorrisonSaunders \& Arts, 2003, 2004).

Following a review of literature and in-depth case study analysis, Palframan (2010) highlights that "there is most potential for environmental benefit from linking EIA with EMS in sectors where organisations plan their own development for which they also oversee construction, occupy and/or operate". Similarly, for three developer interviewees belonging to organisations who continued to manage the project post-construction and during the operational phase, it was conveyed that the links between EMS and EMPs exist and work well. For example, one interviewee remarked "Yes, in my opinion our EMS is very informative and tells us as a developer what should be included in 573 our EMP, how to manage the project on the ground, and sets out how it 574 should be monitored to proceed into the operational phase. Eventually, 575 the EMS takes over and looks after the finished scheme when it becomes 576 part of our day-to-day activities" (D2b). Such findings are also reflective 577 of the detailed documentation of a single organisation's EIA-EMS link- 578 ages, utilising EMPs, undertaken by Marshall (2002, 2004 \& 2005); it 579 is noted that "in the absence of statutory requirements, the develop- 580 ment of an EMP will be motivated by a proponent/developer's individ- 581 ualistic desire to satisfy specific project requirements or for them to fit 582 within existing management frameworks such as their EMS". It is 583 reported that a proactive approach to EIA follow-up can enhance devel- 584 opmental success and "keep an eye on" the final outcome using a num- 585 ber of EMS/EMP approaches (Marshall, 2004).

Marshall (2004) also recognises that follow-up leads to improved 587 interaction with stakeholders. This sits in contrast to a developer inter- 588 viewee's response, who remarked that "For us, the links and the processes 589 we undertake work really well, but stakeholders don't take an interest. So I 590 guess you could argue that it is up to the individual company to make sure 591 that those conditions are discharged responsibly - this is within our system 592 and we would do that - I send out the information to them - whether 593 anybody looks at it I have no idea, and the whole system lacks stakeholder 594 communication" (D1). Thus, despite successful EMP-EMS linkages being 595 evident within some organisations, it is clear that there are still 596 weaknesses in the process, in this case the distinct lack of communica- 597 tion between stakeholders which must be addressed.

For those development projects where the operational phase is 599 taken over by another company or where multiple parties are involved 600 rather than a single project proponent, several challenges were 601 highlighted. One developer stressed "Despite agreements that may have 602 been made with the statutory consultee during the project, the land may 603 not be designated and so future site managers will not consult the statutory 604 body and all that work is put to waste. Different specialists are consulted. 605 Information is lost, definitely" (D3a). Such difficulties align with the find- 606 ings of Slinn et al. (2007) who highlight the challenges when multiple 607 parties take ownership at each stage of the development, with environ- 608 mental management requirements more in evidence when the devel- 609 oper maintains a longer-term leasehold interest. These weaknesses 610 demonstrate the considerable need for information to be retained and 611 suitably transferred across the project lifecycle, perhaps also largely 612 attained through an increase in communication between stakeholders. 613

There is demonstrable literature regarding EMS that highlights not 614 only the tangible benefits, but also the 'intangible' environmental per- 615 formance improvements such as increased environmental awareness 616 among employees (Rondinelli \& Vastag, 2000). The case study 617 documented by Marshall (2002, 2004, 2005), and the opinions of all de- 618 veloper interviewees in this study, are indicative that the presence of a 619 developer's EMS can drive proponents to go above and beyond the re- 620 quirements of initial EIA and to enhance environmental management 621 through the production of an EMP. For consultants, however, opinions 622 varied as to whether the presence of their company EMS affected 623 good practice; half were not even aware of the contents of their EMS, 624 inhibiting further development on this subject area.

Similarly, opinions on whether the presence of another organisa- 626 tion's EMS contributed to better practice produced a mixture of re- 627 sponses. For the majority of developers and consultants, organisations 628 with an EMS were more environmentally aware, but some were of the 629 impression that the EMS only affected good practice at a basic level. 630 For example, one developer notes "I think it is challenging for bigger orga- 631 nisations to be aware of their EMS and to have a buy-in to it and to actively 632 contribute to it - inevitably you became a little distant. So yes it might 633 affect practice, but only a little I think" (D3b). Further adding to the vari- 634 ation, local authority interviewees were of the impression that the mon- 635 itoring and follow-up requirements were dependent on the developer, 636 advocating that those who were more environmentally aware were 637 more likely to report back on the monitoring specified in the EMP. 
Although the local authority interviewee comments are only inexplicitly linked to the enhanced environmental performance improvements provided by an organisation's EMS (due to the lack of EMS knowledge shown by this stakeholder group), given that the majority of stakeholders were of the impression that EMS does promote better practice, it is tempting to advocate that the culture of an organisation, as informed by an EMS, leads to improved production and implementation of an EMP. However, what certainly cannot be discounted is the apparent need for stakeholders to be encouraged to broaden their knowledge of environmental tools so that EMS and its potential linkages with EMPs can be further understood. Until then, it seems that the intangible environmental performance benefits of EMS cannot be fully appreciated.

A final but equally significant point to note for this subject area is the number of interviewees who reflected on how interesting it was to discuss the linkages between the two environmental management tools, further strengthening the requirements for stakeholders to gain an extended knowledge of environmental management tools from what seems to be, for many, a starting point of low awareness.

\section{Future improvements to EMPs as a follow-up tool are required}

Guidance by professional bodies (e.g. IEMA, 2008) can give rise to the development of communities of practice (Lave \& Wenger, 1991), and it is noted that this has potentially been instrumental in the rise of EMP use in the UK, but that more is needed (Durning, 2012). The majority of interviewees (95\%) and survey participants (88\%) agreed that improvements to advance the effectiveness of EMPs as an EIA follow-up tool were needed, and were able to provide at least one improvement, if not several.

The most commonly recurring improvement was the desire for both EMPs and monitoring to be legal requirements, felt by all local authority and statutory consultee interviewees, and the majority of survey participants. Such suggestions for improvement reflect the widespread recognition for a number of years that strengthened EIA regulations focusing on monitoring and follow-up would improve practice of EIA and the linkages with ongoing environmental management (ODA, Overseas Development Administration, 1998; Dipper et al., 1998; Morrison-Saunders \& Arts, 2004; Wood, 1999; Tinker et al., 2005; Jay et al., 2007; Slinn et al., 2007). Specifically focusing on EMPs, Tinker et al. (2005) suggests that in order for EMPs to be relied on as an effective protection tool to implement mitigation measures, they need to be made a legal requirement. Furthermore, IEMA (2008) highlight that the lack of statutory requirements for EMPs has resulted in their use to vary significantly within sector, organisation and scheme. After years of receiving such little uptake, monitoring appears to have been recently strengthened through the new EIA Directive (2014). How this will change things remains to be seen and will depend on the strength of new domestic regulations; already UK regulators have an opportunity to make EMPs, when necessary, a legal requirement set by planning conditions in order to improve EIA follow-up and lead to a more consistent practice. It is also important to note that the provision of adequate resources in terms of both finance and capacity needs to be taken into account with the implementation of these new regulations (MorrisonSaunders et al., 2003).

Building on studies from different countries, Morrison-Saunders et al. (2003) note that having regulations in place is clearly an important first step in EIA follow-up, but that the presence of regulations does not necessarily guarantee that follow-up actually occurs in practice; see for example Van Lamoen and Arts (2002) and Dayo et al. (2002). In addition, more recent research carried out by Mordue (2008) using evidence from numerous countries with different legislative systems and cultures, shows that even when post-EIA monitoring is a statutory requirement there is still considerable room for improvement; regulation alone is not sufficient to instigate an effective monitoring regime due to reasons such as the lack of resources, lack of expertise and inadequate techniques (Durning, 2012). These aspects have also been advocated 703 by interviewees; for example, necessary improvements suggested by 704 local authority participants and two consultants included that EMPs 705 should be more project-specific, due to the number of "generic 706 CEMPs" (LA2) and should be written by professionals so that mitigation 707 and monitoring are suited to each project.

A recurring improvement noted by stakeholders was the need for an 709 accessible central database to share experiences of the use of EMPs and 710 the mitigation and monitoring put in place, to enhance future practice. 711 Although not directly a central database, Morrison-Saunders et al. 712 (2003) document the EIA Ordnance website established by the Environ- 713 mental Protection Department, encouraging project proponents to 714 present EIA and environmental monitoring and audit (EMA) informa- 715 tion in multi-media formats. Such a website requires significant invest- 716 ment in sophisticated information technology infrastructure, but brings 717 substantial advantages including easy maintenance and free access to 718 information for the public (Hui and Ho, 2002). This idea of central 719 knowledge sharing has also been used by other organisations; the 720 Department of Energy (DOE), for example, has a Corporate Lessons 721 Learned Database, used to collect and share lessons learned and best 722 practice pertaining to all DOE activities (DOE, 2015). In order for the Q15 central database to be as accessible as possible, we suggest for it to be 724 held online by either IEMA, or perhaps a more local central database 725 hosted by the Local Planning Authority, which stakeholders could access 726 for local knowledge and experiences.

727

Another set of improvements, identified by consultant and develop- 728 er interviewees, revolved around improved communication. This was, 729 as stated above, highlighted as a useful and promising avenue for 730 strengthening the practice of EIA follow-up (Arts et al., 2001), and has 731 been advocated for in later literature (e.g. Morrison-Saunders \& Arts, Q16 2003, 200). Certainly the lack of communication between stakeholders 733 has become a recurring theme in the previous subject areas explored 734 too, and should be a focus for moving practice forward. However, the 735 consultant respondents from the practitioner survey indicated the 736 need for improved writing style, so that EMPs are consistently clearly 737 written. Such differences, not only between stakeholders but also with- 738 in stakeholders groups, are indicative of the variation in the use of EMPs 739 in practice and the various meanings they present to different people. 740

EMPs, as environmental management tools, have the flexibility to 741 suit individual project circumstances and to adapt with experience 742 (Wlodarczyk, 2000; Marshall, 2004; IEMA, 2008). Despite this, inter- 743 viewees advocated the need for greater flexibility within the EMP. One 744 consultant also felt that "often there is not a lot of flexibility in terms 745 of refining it and optimising it in terms of reducing environmental 746 impacts" (C10). As such, it seems that either practice varies, owing to 747 the fact that this improvement was not noted by all participants, or 748 perhaps that their value as a flexible tool is simply not known.

749

The variety of views on improvements to EMPs can only further 750 highlight the variation in practice that currently exists with the use of 751 EMPs.

\subsection{Moving practice forward: thoughts on further enhancement}

753

This study describes some apparent weaknesses in the semi- 754 formalised process outlined by IEMA (2008) (Fig.1). Suggestions for 755 improvements to the idealised linkages between EIA, EMPs and EMS 756 can be seen in Fig. 5, and reflect the stakeholder views from our 757 interviews and surveys.

There is an apparent desire for stakeholders to be informed of the 759 outcomes of an EMP, and it is suggested that EMPs become a legal 760 requirement, as well as the suggested creation of a central database 761 with project outcomes readily available to all stakeholders. In terms of 762 the preparation of the EMP, it is suggested that EMPs are consistently 763 project-specific and written by environmental professionals. The pro- 764 duction of formal guidelines that are specifically targeted towards 765 explaining how an EMS can be successfully implemented into an EMP 766 
framework are suggested to improve the incorporation of both the contractor and the client/proponent EMSs. In addition, the loss of information once a project is in operation requires information to be retained by relevant stakeholders, and for improved communication between stakeholders during project handovers, to ensure environmental protection across the life of the project.

\subsection{Limitations and scope for future research}

This research is the first broad-scale study on the opinions of the range of stakeholders involved in EMPs. However, several difficulties were experienced during the study, placing limitations on the project. A wider range of stakeholders would be preferable with better representation from planners and contractors. The sample size of the questionnaire survey was smaller than we hoped and thus precluded quantitative analysis, but offers reasonable breadth of stakeholder groups and allows some qualitative triangulation of points merging from the interviews.

A systematic review of EMPs was intended as part of this study, but their availability was very limited, due to their confidential status. This not only reduced the quantity of data available for analysis, but also highlighted the significant challenges present in terms of improving EMPs for the future if their availability is prohibited to the researcher or, for that matter any wider stakeholder groups. Future research should aim to focus on specific case study examples, providing opinions on each case study from a range of stakeholders, to further enhance knowledge of EMPs. In addition, academics could build upon the advantages and disadvantages of creating a central database to document lessons learned and improve knowledge, and perhaps raise the idea with IEMA and/or Local Planning Authorities, and document their responses.

\section{Conclusions}

Despite semi-formalised guidance existing for EMPs in the UK since 2008 , and the increasing pressure on stakeholders to prevent or reduce environmental impacts, it is evident that the use and effectiveness of EMPs as an EIA follow-up tool vary considerably in practice, with EMPs only partially fulfilling their bridging role. There is no 'gold standard' terminology for EMPs, all having slightly different uses, and thus presenting different focuses to different stakeholders. Despite variations in practice, the majority of stakeholders were of the opinion that there existed a considerable lack of communication, with local authority and statutory consultee interviewees in particular not being informed of the monitoring results in an EMP, whether conditioned or not, and stakeholders advocating a strong desire to be notified of project results to improve knowledge for future practice.

Stakeholder opinions on the links EMPs can make with an organisation's EMS have also been shown to vary in practice; EMPs have shown to effectively 'bridge the gap' between the construction and operational phase of a project when the project proponent has involvement at all stages, but there are, however, apparent weaknesses and variation in the linkages that EMPs can make with the wider operational management, particularly when multiple parties are involved at differing stages of a project.

Opinions on the awareness of EMSs as an environmental management tool varied across all stakeholders. In some instances, the presence of an EMS and whether this influences good practice was simply not known, and often stakeholders highlighted considerable disinterest in the tool. For others, an EMS was said to better environmental awareness, but only at a basic level. Such aspects are reflective of the prominent specialist focus stakeholders have shown to a single environmental protection tool, rather than having knowledge regarding the wider links that can be made between tools during follow-up, which could potentially increase the chances of more succinct EIA follow-up in the future. For many stakeholders, it was advocated that discussing the links and 'taking a step back' was a novel, yet interesting experience, highlighting an overwhelming need for the linkages between EMPs 829 and EMSs to be made more apparent, and thus possibly leading to 830 stakeholders becoming familiar with more than one part of the overall 831 process.

Updated and more formal guidance, perhaps emerging from the 833 2014 EIA Directive represent opportunities to formalise the process 834 and widen the delivery of good practice across Europe. This change in 835 legislation should, however, be coupled with the additional improve- 836 ments highlighted above, to ensure practice is effectively enhanced 837 to suit all stakeholders. In the meantime, those involved should be 838 encouraged to consider the potential benefits of EMPs, linked when 839 appropriate to wider corporate good practice, which our study has 840 identified.

Malcolm Hudson is Associate Professor in Environmental Science. 842 His research interests include ecosystem services in tropical forests 843 and urban environments, environmental impact assessment and 844 environmental monitoring of human impacts.

\section{Uncited references}

Briggs and Hudson, 2013

IEMA, 2011

Tomlinson, 1997

848

Treweek, 1996

849

World Bank, 1999

\section{Acknowledgements}

We are grateful to the interviewees who took time out to provide us 853 with their insightful experiences and opinions, and for the participants 854 who spared their time to answer the questionnaire. Thank you also to 855 the Chartered Institute of Ecology and Environmental Management, 856 the Association of Local Government Ecologists, and the Institute of 857 Environmental Management and Assessment, for providing the means 858 to distribute the questionnaire. We would also like to thank three 859 anonymous reviewers for their care in reading our manuscript and 860 their helpful comments.

\section{References}

Arts, J.P., Caldwell, P., Morrison-Saunders, A., 2001. Environmental Impact Assessment 863 follow-up: good practice and future directions - findings from a workshop at the 864 IAIA 2000 Conference. Impact Assess. Proj. Apprais. 19 (3), 175-185.

Bird, C.C., 2005. How I stopped dreading and learned to love transcription. Qual. Inq. 11, 866 $226-248$.

yatzis, R.E., 1998. Transforming qualitative information: thematic analysis and code 868 development. Sage.

Boyden, A., 2002. Keeping a promise: the implementation of mitigation measures in en- 870 vironmental impact assessment. Paper presented at IAIA'02 Assessing the Impact of 871 Impact Assessment: Impact Assessment for Informed Decision-making, IA follow- 872 up workshops, 15-21 June, The Hague, The Netherlands, published on CD ROM, 873 Assessing the Impact of Impact Assessment 15-21 June 2002 - All Conference Documents 874 (IAIA and VVM).

Braun, V., Clarke, V., 2006. Using thematic analysis in psychology. Qual. Res. Psychol. 3, 876 77-101.

Briggs, S.L.K., 2006. Do Environmental Management Systems Improve Performance? 878 Standards Outlook, Quality Progress, pp. 78-80 879

Briggs, S., Hudson, M.D., 2013. Determination of significance in Ecological Impact 880 Assessment: past change, current practice and future improvements. Environ. Impact 881 Assess. Rev. 38, 16-25.

Broderick, M., Durning, B., 2006. Environmental Impact Assessment and Environmental 883 Management Plans - an example of an integrated process from the UK. In: Martin- 884 Duque, J.F., Brebbia, C.A., Emmanouloudis, D., Mander, U. (Eds.), Geo-Environment 885 and Landscape Evolution II WIT Transactions Ecology and the Environment vol. 89. 886 WITPress, Southampton.

ayo, F Ajakaiye, B, Eke N Omoloyin, O Adinye, P. 2002. Environmental assessment 888 follow-up program as a component of the Nigerian EIA process: an appraisal. Paper 889 presented at IAIA'02 Assessing the Impact of Impact Assessment: Impact Assessment 890 for Informed Decision-making, IA follow-up workshops, 15-21 June, The Hague, The 891 Netherlands, published on CD ROM, Assessing the Impact of Impact Assessment 15-21 892 June 2002 - All Conference Documents (IAIA and VVM).

Dipper, B., Jones, C., Wood, C., 1998. Monitoring and post-auditing in environmental 894 impact assessment: a review. J. Environ. Plan. Manag. 41, 731-747.

\section{.}


Dik, H., Morrison-Saunders, A., 2002. The influence of EIA approval conditions on environmental practices. Paper presented at IAIA'02 Assessing the Impact of Impact Assessment: Impact Assessment for Informed Decision-making, IA follow-up workshops, 15-21 June, The Hague, The Netherlands, published on CD ROM, Assessing the Impact of Impact Assessment 15-21 June 2002 - All Conference Documents (IAIA and VVM).

Durning, B., 2012. Environmental Management Plans - Origins, Usage and Development In: Perdicoulis, A., Durning, B., Palframan, L. (Eds.), Furthering Environmental Impact Assessment. Edward Elgar Publishing Limited.

Eccleston, C., Smythe, R., 2002. Integrating environmental impact assessment with environmental management systems. Environ. Qual. Manag. 1-13.

Finkbeiner, M., Wiedemann, M., Saur, K., 1998. A comprehensive approach towards product and organisation related environmental management tools: life cycle assessment (ISO 14040) and environmental management systems (ISO 14001). Int. J. Life Cycle Assess. 3 (3), 169-178.

Foody, W., 1993. Constructing Questions for Interviews and Questionnaires. Cambridge University Press, Cambridge.

Fuller, K., Vetori, C., Munro, B., House, K., 2012. EIA-EMS link from the flood risk management sector. In: Perdicoulis, A., Durning, B., Palframan, L. (Eds.), Furthering Environmental Impact Assessment. Edward Elgar Publishing Limited.

Gallardo, A.L.C.F., Sanchez, L.E., 2004. Follow-up of a road building scheme in a fragile environment. Environ. Impact Assess. Rev. 24 (1), 47-58.

Glasson, J., Therivel, R., Chadwick, A., 2013. Introduction to Environmental Impact Assessment. Routledge.

Hammond, R.A., Hudson, M.D., 2007. Environmental management of UK golf courses for biodiversity - attitudes and actions. Landsc. Urban Plan. 83, 127-136.

Holbrook, A.L., Green, M.C., Krosnick, J.A., 2003. Telephone versus face-to-face interviewing of national probability samples with long questionnaires. Public Opin. Q. 67, 79-125.

Hollands, R., Palframan, L., 2014. EIA and EMS integration: not wasting the opportunity. Impact Assess. Proj. Apprais. 32 (1), 43-54.

Hui, S., Ho, M., 2002. e-IA follow-up: internet-based reporting. Paper presented at IAIA'02 Assessing the Impact of Impact Assessment: Impact Assessment for Informed Decision-making, IA follow-up workshops, 15-21 June, The Hague, The Netherlands, published on CD ROM, Assessing the Impact of Impact Assessment 15-21 June $2002-$ All Conference Documents (IAIA and VVM).

IEMA, 2008. Practitioner: Environmental Management Plans. Best Practice Series 12, IEMA. IEMA, Lincoln.

IEMA, 2011. Special Report - State of Environmental Impact in the UK Available at: www.iema.net (Last accessed August 2014).

ISO, International Organization for Standardization, 2015. ISO14001 Environmental Management Systems - Requirements with Guidance for Use. ISO. http://www.iso.org/ iso/catalogue_detail?csnumber $=60857$ (Last accessed 17 September 2015).

ISO, International Organization for Standardization, 2013. The ISO Survey of Management System Standard Certifications. p. 2013 Available at: http://www.iso.org/iso/iso_ survey_executive-summary.pdf (Last accessed March 2015).

Jay, S., Jones, C., Slinn, P., Wood, C., 2007. Environmental impact assessment: retrospect and prospect. Environ. Impact Assess. Rev. 27 (4), 287-300.

Lave, J., Wenger, E., 1991. Situated Learning - Legitimate Peripheral Participation. Cambridge University Press, Cambridge.

Fink, A., 2003. How to Manage. Sage Publications Ltd, Analyse and Interpret Survey Data.

Fink, A., Kosekoff, J., 1998. How to Conduct Surveys: A Step-By-Step Guide. Sage Publications, Inc.

Lewis, B., Griffiths, R.A., Wilkinson, J.W.W., Arnell, A., 2014. Examining the fate of local great crested newt populations following licensed developments. Report WM0231 to DEFRA (UK).

Marshall, R., 2002. Developing environmental management systems to deliver mitigation and protect the EIA process during follow up. Impact Assess. Proj. Apprais. 20 (4), 286-292.

Marshall, R., 2004. Can industry benefit from participation in EIA follow-up? In: MorrisonSaunders, A., Arts, J. (Eds.), Assessing Impact. Earthscan, London, pp. 118-153

Marshall, R., 2005. Environmental impact assessment follow-up and its benefits for industry. Impact Assess. Proj. Apprais. 23 (3), 191-196.

Mohamad-Said, A., 2002. Environmental impact assessment post-monitoring in Malaysia - lessons from case studies. Paper presented at IAIA 02 assessing the impact of impact assessment: Impact assessment for informed decision-making, IA follow-up workshops, 15-21 June, The Hague, The Netherlands, published on CD ROM. Assessing the Impact of Impact Assessment 15-21 June 2002 - All Conference Documents (IAIA and VVM)

Mordue, M., 2008. The Monitoring of Mitigation Measures in Environmental Impact Assessment. Oxford Brookes University, Oxford MSc Dissertation.

Morrison-Saunders, A., Baker, J., Arts, J., 2003. EIA follow-up - lessons from practice: towards successful follow-up. Impact Assess. Proj. Apprais. 21 (1), 43-56.

Morrison-Saunders, A., Arts, J., 2004. Introduction. In: Morrison-Saunders, A., Arts, J. (Eds.), Assessing Impact: Handbook of EIA and SEA Follow-up. Earthscan, London, pp. 1-21.
Morrison-Saunders, A., Marshall, R., Arts, J., 2007. EIA Follow-Up: International Best 971 Practice Principles. Fargo, Farg, ND.

Morrow, D., Rondinelli, D., 2002. Adopting corporate environmental management sys- 973 tems: motivations and results of ISO14001 and EMAS certification. Environ. Manag. 974 J. 20 (2), 159-171.

Nitz, T., Holland, I., 2000. Does environmental impact assessment facilitate environmental 976 management activities? J. Environ. Assess. Policy Manag. 2 (1), 1-17. 977

Obradovic, V., 2011. Linking EIA with EMS: the way to environmental protection 978 excellence. IPMA 25th World Congress. Brisbane, Australia.

ODA (Overseas Development Administration), 1998. The Manual of Environmental 980 Appraisal. ODA, London.

Oppenheim, AN 1992. Questionnaire Design. Pinter Publishers Itd, Interviewing and Attitude Measurement. $\quad 983$

Palframan, L., 2010. The Integration of EIA and EMS systems: experience from the UK. 984 30th Annual Conference of IAIA Proceedings. 985

Perdicoulis, A., Durning, B., Palframan, L., 2012. Furthering Environmental Impact 986 Assessment: Towards a Seamless Connection between EIA and EMS. Edward Elgar 987 Publishing Limited.

Ridgway, B., 2005. Environmental management system provides tools for delivering on 989 environmental impact assessment commitments. Impact Assess. Proj. Apprais. 23990 (4), 325-331.

Ritchie, J. Spencer, L, 1994. Qualitative data analysis for applied policy research. In: 992 Burgess, R.G. (Ed.), Bryman, A. Analysing Qualitative Data, pp. 173-194. 993

Rondinelli, D., Vastag, G., 2000. Panacea, common sense, or just a label? The value of ISO 994 14001 environmental management systems. Eur. Manag. J. 18 (5), 499-510. 995

Sánchez, L., Hacking, T., 2002. An approach to linking environmental impact assessment 996 and environmental management systems. Impact Assess. Proj. Apprais. 20 (1), 25-38. 997 Siedman, I., 2006. Interviewing as Qualitative Research. 3rd ed. Teachers College Press. 998

Slinn, P.., Handley. J. Jay, S., 2007. Connecting EIA to environmental management systems: 999 lessons from industrial estate developments in England. Corp. Soc. Responsib. 1000 Environ. Manag. 14, 88-102.

Tinker, L., Cobb, D., Bond, A., Cashmore, M., 2005. Impact mitigation: impact mitigation in 1002 environmental impact assessment: paper promises or the basis of consent 1003 conditions? Impact Assess. Proj. Apprais. 23, $4 . \quad 1004$

Tomlinson, P., 1997. From environmental statement through to implementation. Environ. 1005 Assess. 5, 39-41.

Treweek, J., 1996. Ecology and environmental impact assessment. J. Appl. Ecol. 33 (2), 1007 191-199.

Van Lamoen, F., Arts, J., 2002. EIA follow-up for road projects: what do we want and need 1009 to know? Paper presented at IAIA'02 Assessing the Impact of Impact Assessment: Im- 1010 pact Assessment for Informed Decision-making, IA follow-up workshops, 15-21 June, 1011 The Hague, The Netherlands, published on CD ROM, Assessing the Impact of Impact 1012 Assessment 15-21 June 2002 - All Conference Documents (IAIA and VVM). 1013

Wessels, J.A., 2013. Factors that influence the independence of EIA follow-up verifiers: a 1014 developing country perspective. Impact Assess. Proj. Apprais. 31 (1), 169-179. 1015

Wlodarczyk, T., 2000. Improving monitoring and follow-up in Canadian Environmental 1016 Assessments', presented at Back to the Future: Where will Impact Assessment be in 101017 years and How Do We Get There? 20th Annual Meeting of the International Association 1018 for Impact Assessment, 9-13 June 2000, Hong Kong Convention and Exhibition Centre, 1019 Hong Kong

Wood, G., 1999. Post-development auditing of EIA predictive techniques: a spatial analyt- 1021 ical approach. J. Environ. Plan. Manag. 42, 671-689.

World Bank, 1999. Environmental Management Plans. Available at: http://web. 1023 worldbank.org/WBSITE/EXTERNAL/PROJECTS/EXTPOLICIES/EXTOPMANUAL/0, 1024 contentMDK:20065218 menuPK:64701637 pagePK:64709096 piPK: 1025 64709108 theSitePK:502184,00.html (Last accessed September 2014). $\quad$ Q18

Sophie Bennett is a graduate Environmental Scientist for Mott MacDonald, with previous 1028 experience in local authorities, ecological consultancy and environmental NGOs. 1029

Simon Kemp is a Professorial Fellow in Environmental Science, with wide-ranging 1030 experience in delivering sustainability initiatives with businesses and the HE sector, as 1032 well as consultancy focussing on environmental management systems, which he also 1033 teaches to postgraduate level.

Malcolm Hudson is Associate Professor in environmental science. His research interests 1036 include ecosystem services in tropical forests and urban environments, environmental 1037 impact assessment and environmental monitoring of human impacts 